\title{
How can I get that good grade again? Improving Pasifika student achievement in NCEA with a motivation intervention
}

\author{
Peter Sanders and Andre Boyte \\ a St Mary's College, Wellington \\ ${ }^{b}$ Victoria University of Wellington
}

\begin{abstract}
Students who are underachieving in secondary school are likely to hold maladaptive motivation orientations that, unless changed, will have a negative impact on their future achievement. In this study 57 students from two schools with large Pasifika populations were offered supplementary teaching and learning opportunities via two different study skills programmes to improve their motivation and achievement. Participants (including 28 Pasifika students) were randomly assigned to either a traditional study skills (TS) or a motivation-enhanced study skills (MS) programme. NCEA results showed that students in the MS intervention attained more credits and showed significantly greater reduction in the negative motivation orientation uncertain control, compared to students in the TS skills programme. Students also reported that their relationships with their teachers and how their teachers communicated with them about learning was important to their motivation and achievement. Based on these findings, recommendations are made for teacher use of internally assessed NCEA standards as the context for interventions designed to enhance student motivation and achievement, in light of proposed changes to NCEA.
\end{abstract}

Keywords: motivation, achievement, Pasifika, secondary school, assessment

\section{Introduction}

The under-achievement of some students in New Zealand secondary schools concerns educators, academics and policy-makers in the Ministry of Education. Of particular concern are ethnic patterns that show that Pasifika students have lower achievement outcomes compared to students from most other ethnic groups. For example, in $2018,39.4 \%$ of school/kura leavers attained a University Entrance Award. Asian learners/ākonga had the highest proportion of school/kura leavers attaining a University Entrance Award with 65.4\%, while $43.9 \%$ of European/Pākehā learners/ākonga attained it, as did $21.9 \%$ of Pacific students/ākonga, and 18.6\% of Māori learners/ākonga (Education Counts, 2019).

To gain more data about what motivates Pasifika students to work hard, this research focused on how motivation is related to achievement, and how motivation may have been affected by an intervention programme. The research was conducted within the context of culturally responsive teacher-student relationships which is consistent with the Teu le va research principles. These call for "strategic, evidence-based, outcomes-focused Pasifika success where every Pasifika learner in New Zealand should succeed educationally to maximise the exposing of Pasifika voices, and the issues and concerns of Pasifika learners so that new knowledge and understandings are generated" (Airini, 2010, p. 37). 
Students in New Zealand secondary schools attempt to gain qualifications for the National Certificate of Educational Achievement (NCEA). This means that student learning is assessed against agreed standards set by the New Zealand Qualifications Authority (NZQA). Teachers can choose to internally assess student work against standards depending on what rules are set by NZQA. A moderation process, both within schools and between schools, is common practice to ensure integrity of the internal assessment. There are three levels of the NCEA, levels one, two and three, which students usually work through in years 11,12 and 13 (NZQA, 2019).

\section{Motivation and achievement}

Consider how an underachieving year level 11 Pasifika student faced with level one NCEA for the first time may feel about their chances of academic success when their prior achievement in assessments was low. This could be because prior achievement is correlated with subsequent achievement at school (Hattie, 2009). Very likely most Year 11 students will have a clear self-perception of how well they are going to do in NCEA based upon prior achievement results. Hattie (2009) reported that high school students are accurate in their self-assessment and their understanding of their achievement levels across all subjects, and Kuncel, Crede, and Thomas (2005) suggested that students' performance in assessments may be limited by their pre-conceptions about their own ability.

Repeated underachievement may lead students to believe that they are 'dumb'. Chodkiewicz and Boyle (2014) reported that although one student may fail a test and believe they should try harder for the next assessment, another student who fails the test may "exert even less effort since he or she may be thinking 'why try if I am too stupid to succeed anyway?"' (p. 79). Chodkiewicz and Boyle concluded that the students' feelings about why they failed or succeeded in an assessment will mediate their reaction to future test situations. Consider the effect that repeated underachievement may have on a student's motivation towards their school work. What sort of negative motivation concepts might an underachieving student have built up over their preceding years of poor assessment results?

Motivational approaches to schoolwork may be either adaptive or maladaptive. Adaptive motivation orientations include persistence and self-belief, whereas maladaptive motivation orientations include self-sabotage and uncertain control. Students with adaptive motivation orientations may have higher academic achievement outcomes than students with maladaptive motivation orientations. Meyer, McClure, Walkey, McKenzie, and Weir (2006) explained that unless students view ability as an expandable set of skills, they may adopt maladaptive helpless orientations resulting in lower achievement outcomes and that harm can occur if students believe they are simply not smart enough to do what is expected of them in school.

Self-sabotage and uncertain control are examples of intra-personal motivation orientations but research about motivation and achievement should also consider how interpersonal motivation orientations may affect achievement (Meyer, Weir, McClure, Walkey, \& McKenzie, 2009). The view that inter-personal motivation can affect achievement is based on a non-western interpretation of achievement motivation - that students may be motivated to improve achievement by enhancing inter-personal concepts such as peer, teacher and/or family affiliation. 
Underachieving students may hold more maladaptive motivation orientations than higher achieving students. Chodkiewicz and Boyle (2014) explained that "it is advantageous to have a slightly optimistic perception of one's capabilities" and

that students who hold an adaptive attributional style may attribute success to their ability, and their failure to lack of effort. However, students who hold a maladaptive attributional style may believe that there is nothing they can do about their achievement and their continual poor results in tests because fundamentally they are 'thick.' (p. 79)

\section{Intervention programmes associated with motivation and achievement}

Research shows that motivation and achievement may be altered by intervention (Cohen, Garcia, Apfel, \& Master, 2006; Cohen, Garcia, Purdie-Vaughns, Apfel, \& Brzustoski, 2009; Harackiewicz, Rozek, Hulleman, \& Hyde, 20, 12). Related research shows that even short interventions can have a positive effect. For example, Cohen (2011) discussed identifying "the pressure points where a small nudge might have large consequences" (p. 178). Paunesku (2013) reported that "Over the last several decades, a handful of seemingly small psychological field interventions, lasting hours or even minutes, have affected students' achievement over periods of months or years" (p. 7). Motivation interventions can help underachieving students to understand that their prior views of their "ability" are not fixed and can change in relation to the amount of effort that they put in.

This article focuses on one particular motivation orientation to see if it could be changed by intervention - a student's sense of control over their learning, in particular uncertain control motivation orientations which may be held by underachieving students. If students believe they have some control over how well they do on assessments, there is a higher likelihood they will engage in the necessary study behaviour to do better on future assessments. It is likely that a student who fails enough times will simply stop trying as they may believe that they have little control over how well they do in tests. Control is associated with mastery and hopefulness, and lack of control is associated with helplessness. Control is also related to the idea that people whom students care about demonstrate they value the outcome and ideas about non-contingent or inconsistent feedback. Teachers are central to enhancing the amount of control a student believes they have in an assessment situation. Uncertain control is a particularly damaging motivation concept because students with high uncertain control levels may adopt learned helplessness attitudes towards assessment tasks (Azjen, 2011; Meyer, McClure et al., 2006; Walkey, McClure, Meyer, \& Weir, 2013).

Relevant research about interventions specifically designed to alter motivation orientations include Martin $(2005,2008)$ who used a pre-test, post-test control group design to investigate the impact of an intervention on the motivation and engagement of 53 male high school students in Australia. Martin (2008) reported an improvement in targeted aspects of motivation constructs as evidenced by significant effect sizes ranging from 0.38 to 0.64 in the treatment group, in comparison to the control group. Martin (2008) suggested that further research to test associations between changes in motivation and changes in achievement would be useful. However, the subjects in Martin's research were Australian, male, of European descent and included high-achieving students. In addition, Martin (2005, 2008) examined change in intra-personal motivation and achievement. 
This research aimed to build on New Zealand research about motivation and achievement. For example, Meyer and colleagues investigated the impact of the NCEA on student motivation, the relationship between the NCEA design and student motivation and achievement (Meyer, McClure et al., 2006; Meyer, McClure, Walkey, Weir, \& McKenzie, 2008; Meyer, Weir et al., 2007, 2009). One conclusion from these studies was that interventions that aim to have a long-term impact on student learning outcomes should consider student motivational orientations or the intervention may run the risk of affecting short-term behaviour changes. Meyer, McClure et al. (2009) also encouraged research noting "that highlighted intrapersonal motivation orientations could add significant value to the more traditional approach of academic remediation only" and noted that "Martin's (2008) work in Australia provides an excellent example of this" (Martin, 2008, p. 104).

Meyer (2012) urged that teachers take more responsibility for underachievement, urging educators to intervene through school and teacher practices that are feasible and effective. Meyer also noted that the NCEA standards-based assessment system in New Zealand schools creates opportunities for teachers to do research within their own classrooms "to investigate the kinds of approaches that work not just in principle or theory but make a real difference to educational outcomes for our young people" (p. 311). Robinson and Timperley (2004) and Chu, Glasgow, Rimoni, Hodis, and Meyer (2013) also note that empirical research about the effects of intervention programmes to help improve teaching practice and raise achievement, especially Pasifika student achievement, is critical. Students reported that their relationships with their teachers and how their teachers communicated with them about learning was important to their motivation and achievement.

This article reports on research built on the research described in this section and examines the effects of two intervention programmes on motivation and achievement. The intervention programmes were delivered in a context of culturally responsive teacherstudent relationships with underachieving students, focussing on Pasifika students in New Zealand secondary schools. The article discusses differences in NCEA achievement and changes in uncertain control and self-sabotage motivation outcomes for all students, and Pasifika students who participated in a TS support programme compared to students who participated in a MS support programme. It also discusses student perceptions about uncertain control and self-sabotage motivation outcomes and how these affect their achievement in NCEA. The article may inform teaching practice about how to raise Pasifika student achievement, especially in light of recent proposed changes to internal assessment within NCEA. In 2018, the Minister of Education launched a national conversation on the future of NCEA. Proposed changes relevant to this article include a move to re-balance the number of credits available for internally and externally assessed achievement standards (50:50 split). Achievement standards assessed externally will include exams and other forms of assessment, including portfolios. Another possible change means teacher capability will be strengthened to incorporate mātauranga Māori and more Pacific knowledge (where appropriate) into teaching under NCEA. Finally, there is a proposal to remove Level 1 NCEA to allow teachers to focus more on teaching and less on assessment. By reducing their assessment workload, teachers would be free to develop innovative approaches to year 11 which would be of more value to students than a Level 1 qualification (NZQA, 2019). 


\section{Method}

This research investigated the effects of two different study skills intervention programmes that were delivered to 57 year 11 students at New Zealand secondary schools who were attempting to gain credits for Level 1 of the NCEA. Twenty-seven of the students were Pasifika, and 30 were non-Pasifika. The mean age of participants was 15 years. Students came from low-ability streams and were placed in the MS or TS groups by matched-pair assignment. To get even MS and TS groups, students were ranked by prior level of achievement and then allocated to either the MS or TS intervention study programme. In order to create two similar groups, students were allocated to the MS or TS groups in matched pairs - the top ranked student went into the MS group and the second ranked student to the TS group, and so on until all students were grouped. An assumption of this research was that teaching students how to study is useful because students in the TS group received traditional study skills such as emphasising self-management and persistence whereas students in the MS group had these same traditional study skills supplemented by motivation messages based on previous research about adaptive versus maladaptive motivation orientations. Ethics approval was sought and approved for this research from the Victoria University of Wellington Faculty of Education Ethics Committee SEPI/2010/36: RM 17651.

\section{Description of the MS and TS study-skills programmes}

The modules Martin $(2005,2008)$ used were considered as part of the design of this research but were enhanced both in programme design and delivery by a focus on positive teacherstudent relationships. Martin and Dowson (2009) explain that key motivation theories and achievement can be better understood using the concept of "relationships" as an overarching framework ( $p$. 327). They based their views on relationships, motivation and achievement on the concept of "modelling" of behaviour. If a student has a good relationship with a teacher, then that student may internalise some of the teacher's beliefs and values about schoolwork. For example, if a teacher believed that persistence, goal striving and self-regulation were important to achievement, a student who related well to that teacher is more likely to show enhanced levels of persistence, goal striving and self-regulation.

Both the TS and MS programmes were designed to be positive for student achievement. It was reasonable to expect there could be improved achievement outcomes for Pasifika students from both the MS programme and the TS programme since both programmes provided teaching and learning opportunities. Both programmes offered general study skills, and one-on-one assistance to students, particularly with literacy activities and in other subject areas. However, the MS programme included all these components plus motivation-focused elements. This research was designed to make comparisons about the effectiveness of each of the programmes on motivation outcomes and student achievement. All students received eight hours of the MS or TS study skills programme with the researcher. This time included pre-testing, teaching the study skills programme, assessing students, offering a re-assessment opportunity, and finally post-testing. Then the researcher taught the students in both programmes and at the same time delivered either a motivation-enhanced study (MS) or a traditional study (TS) skills programme. All participating students received formal classroom Mathematics or Science instruction during regular classroom lessons and either the motivation enhanced study skills programme (MS) or a TS-skills programme (TS). 
The TS programme modules were:

$\begin{array}{ll}\text { TS \#1 } & \text { Introductions, explanations and pre-testing } \\ \text { TS \#2 } & \text { Organising my study } \\ \text { TS \#3 } & \text { Managing myself } \\ \text { TS \#4 } & \text { Classwork skills } \\ \text { TS \#5 } & \text { Reading skills } \\ \text { TS \#6 } & \text { Doing assignments } \\ \text { TS \#7 } & \text { Preparing for tests } \\ \text { TS \#8 } & \text { Assessment and post-testing }\end{array}$

The MS programme modules were based on the TS programme but included motivation concepts:

TS \#1 Introductions, explanations and pre-testing

MS \#2 Goals and motivation including a Personal Best (PB) approach to goals

MS \#3 Doing My Best (DMB) and Doing Just Enough (DJE)

MS \#4 Adaptive intra-personal motivation orientations and achievement

MS \#5 Maladaptive intra-personal motivation orientations and achievement

MS \#6 Inter-personal motivation orientations and achievement

MS \#7 Attributions and control and motivation

MS \#8 Assessment and post-testing

\section{Data collection}

This research had a two-phase, sequential, explanatory, mixed-method research design (Creswell, 2009). This was mixed-methods research which pre-tested and post-tested students using Martin's (2008) Student Motivation and Engagement Scale (MES-HS) and Meyer, McClure, et al.'s (2008) Survey of NCEA Goals Year 10 and Year 11 Students to gain quantitative data. Qualitative data about perceptions on motivation and achievement were gained from interviews with students.

A considerable amount of data were gained in this research but this article focusses on two maladaptive motivation orientations and how they may be associated with achievement outcomes. These are uncertain control and self-sabotage. The achievement measure used in this study was the total number of NCEA credits gained at year 11.

\section{Uncertain Control}

Items measuring uncertain control were obtained from the Student Motivation and Engagement Scale (MES-HS; Martin, 2005, 2009). Uncertain control is considered a maladaptive factor. There were four items in the uncertain control measure, for example, "When I don't do so well at school I'm often unsure how to avoid that happening again." Participants responded to each of the items on a 7-point Likert scale, with 1 meaning "Disagree Strongly" and 7 meaning "Agree Strongly." The four responses were averaged together to create an overall score, with a higher score relating to higher self-sabotage. Cronbach's alpha for the self-sabotage scale indicated good internal reliability, both for the pre-intervention $(\alpha=.74)$ and post-intervention $(\alpha=.83)$ scales (Cronbach, 1951). 


\section{Self-Sabotage}

Items measuring self-sabotage were again taken from the MES-HS (Martin, 2005, 2009). Selfsabotage uncertain control is also considered a maladaptive factor. There were four items included in the self-sabotage scale such as "Sometimes I don't try hard at assignments so I have an excuse if I don't do so well." Participants responded to each of the items on a 7-point Likert scale, with 1 meaning "Disagree Strongly" and 7 meaning "Agree Strongly." The four responses were averaged together to create an overall score, with a higher score relating to higher self-sabotage. Cronbach's alpha for the self-sabotage scale indicated good internal reliability, both for the pre-intervention $(\alpha=.86)$ and post-intervention $(\alpha=.92)$ scales (Cronbach, 1951).

\section{NCEA credits}

The achievement measure used in this study was the total number of NCEA credits gained at year 11.

\section{Quantitative data analysis}

Table 1.

Descriptive data showing the means for each motivation orientation and NCEA credits

\begin{tabular}{lcccccccc}
\hline & $\begin{array}{c}\text { Teaching } \\
\text { Style }\end{array}$ & SS Pre & SS Post & SS Change & UC Pre & $\begin{array}{c}\text { UC } \\
\text { post }\end{array}$ & $\begin{array}{c}\text { UC } \\
\text { Change }\end{array}$ & $\begin{array}{c}\text { NCEA } \\
\text { Credits }\end{array}$ \\
\hline Pasifika & MS & 3.71 & 3.48 & -0.23 & 4.29 & 3.89 & -0.39 & 76.50 \\
& TS & 2.92 & 3.48 & 0.56 & 3.69 & 4.00 & 0.31 & 71.67 \\
& Total & 3.35 & 3.48 & 0.13 & 4.01 & 3.94 & -0.07 & 74.27 \\
\multirow{4}{*}{ Non-Pasifika } & MS & 3.21 & 2.92 & -0.29 & 4.14 & 3.66 & -0.49 & 95.79 \\
& TS & 3.27 & 3.32 & 0.05 & 4.25 & 3.43 & -0.82 & 82.71 \\
& Total & 3.24 & 3.12 & -0.12 & 4.20 & 3.54 & -0.65 & 89.25 \\
\hline
\end{tabular}

SS = Self-sabotage; UC = Uncertain control

\section{Descriptive Statistics about Uncertain Control}

\section{Analysis one}

This research investigated changes in uncertain control over time between students in the MS and TS groups. Differences between groups were analysed using a 2 (IV1: Group, 2 levels: MS, TS, IV2 - between subjects) x 2 (IV2: Time, 2 levels: pre-test, post-test) repeated measures ANOVA. Results of the ANOVA revealed a main effect of time $(F(1,54)=5.53, p=.022)$, such that uncertain control decreased at post-test compared to the pre-test for both groups. There was no main effect of group, nor any interaction between group and time (all $p^{\prime} s>.05$ ). Figure 1 below depicts the described results. 


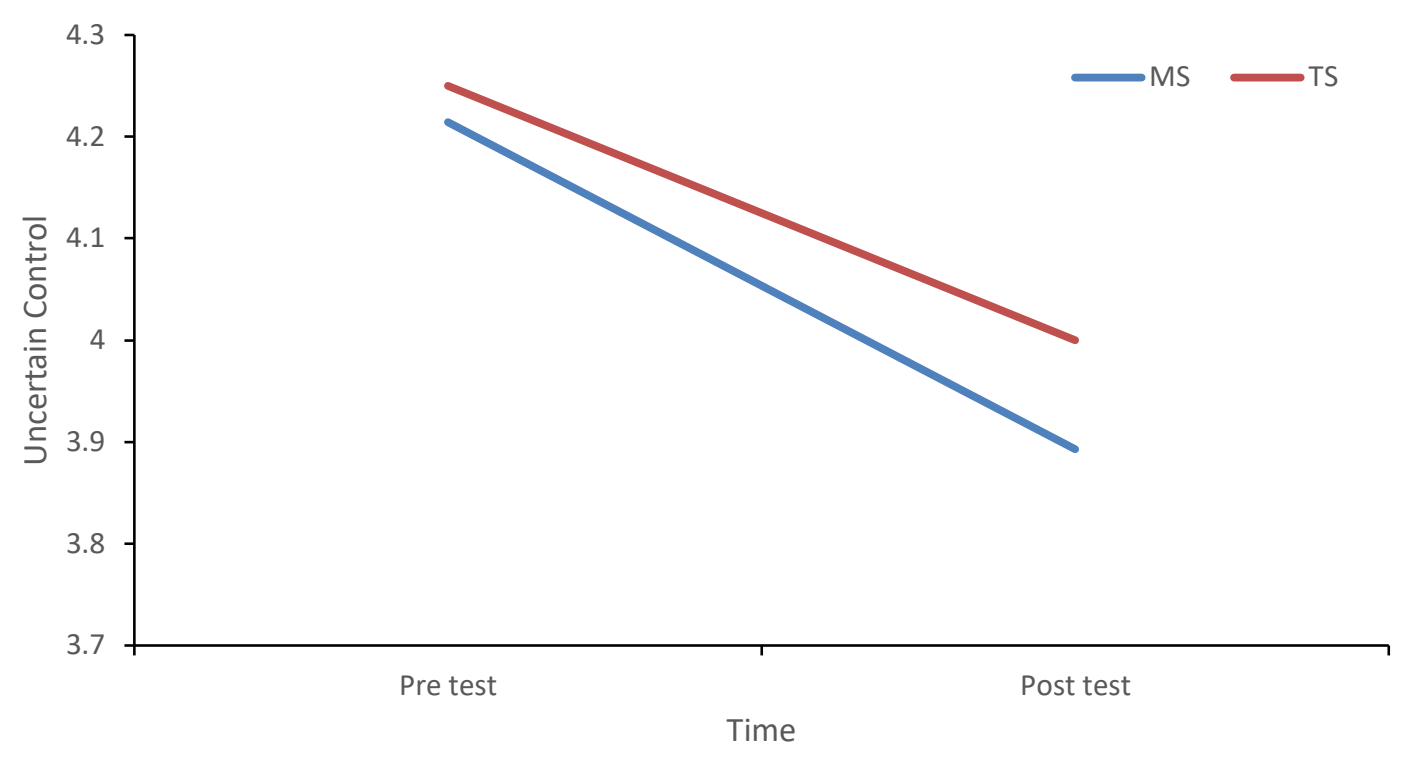

Figure 1. Mean scores for Uncertain Control at pre-test and post-test separated by group condition"

\section{Analysis two}

This research also assessed any changes in uncertain control over time between Pasifika and Non-Pasifika students. Differences in uncertain control over time were analysed using a 2 (IV1: Group, 2 levels: MS, TS - between-subjects) x2 (IV2: Ethnicity, 2 levels: Pasifika, Non-Pasifika - between-subjects) ANOVA. Results of the ANOVA revealed a main effect of ethnicity ( $F$ $\left.(1,52)=4.09, p=.048, \eta_{p}{ }^{2}=.07\right)$ such that the overall decrease in uncertain control was greater for non-Pasifika students compared to Pasifika students. There was no main effect of group $(F(1,52)=0.19, p=.667)$. There was evidence that the interaction between ethnicity and group was trending towards significant $\left(F(1,52)=4.09, p=.093, \eta_{p}{ }^{2}=.05\right)$.

Two separate independent sample t-tests were used to further analyse any potential differences the groups had on Pasifika and non-Pasifika students' uncertain control. For Pasifika students, the independent-sample t-test revealed that those in the MS group ( $M=$ $-.38, S D=.92)$ showed significantly decreased uncertain control compared to those in the TS group $(M=.31, S D=0.51), t(25)=2.34, p=.014$. The measure of effect size, Cohen's $d$, showed a strong difference of effect for Pasifika students in the MS group compared to the TS group $(d=.93)$. The independent sample t-test for non-Pasifika students found no significant difference between change in uncertain control scores for those in the MS group $(M=-.49, S D=1.49)$ compared to those in the TS group $(M=-.90, S D=1.52), t(27)=.74, p$ $=.233$. Figure 2 depicts the results of the above analyses in graph form. 


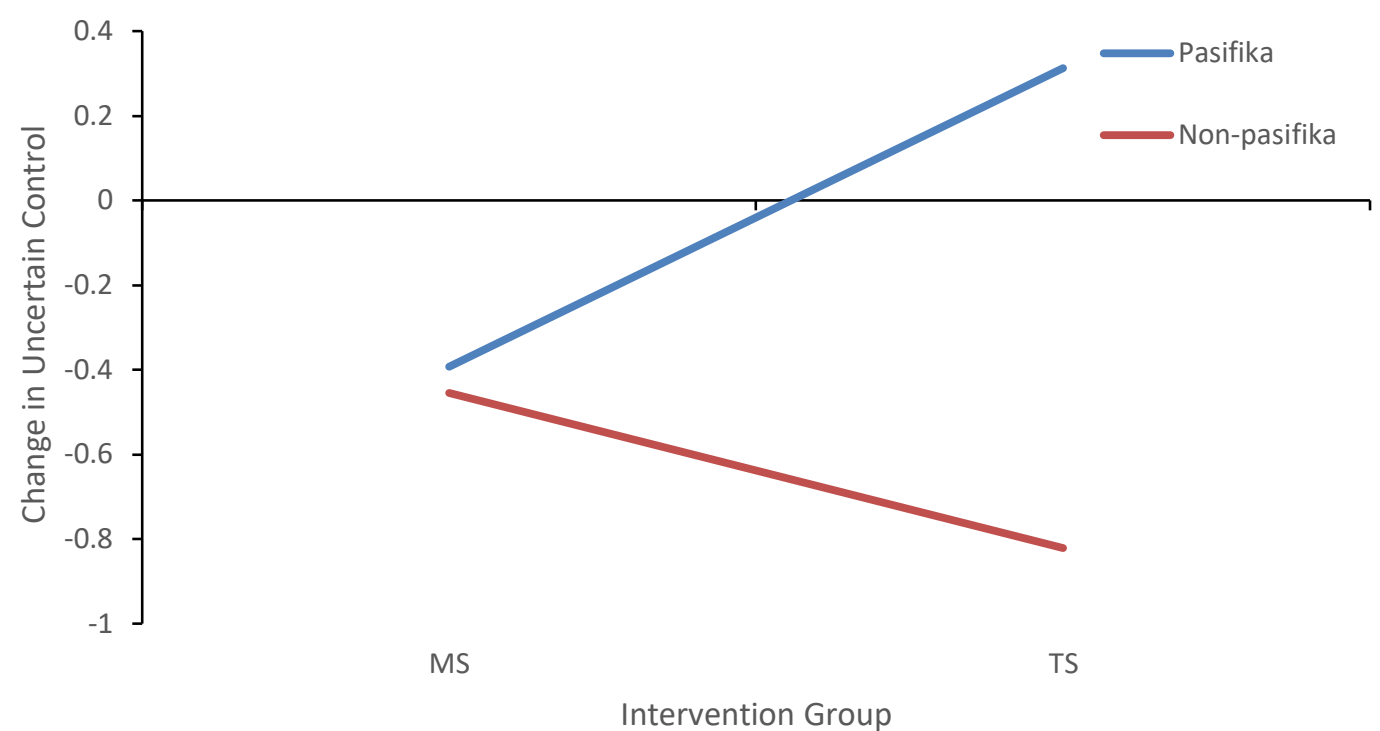

Note: Change scores were calculated by subtracting average Uncertain Control scores at post-test from the average scores at pre-test

Figure 2. Mean change scores for Uncertain Control, separated by ethnicity

\section{Descriptive statistics about Self-Sabotage}

\section{Analysis three}

Differences between MS and TS groups in self-sabotage over time using a 2 (IV1: Group, 2 levels: MS, TS, IV2 - between subjects) x 2 (IV2: Time, 2 levels: pre-test, post-test) repeated measures ANOVA. Results of the ANOVA did not reveal any significant main effects nor any group $x$ time interaction (all $p^{\prime} s>.05$ ). A depiction of this analysis is shown in Figure 3 below.

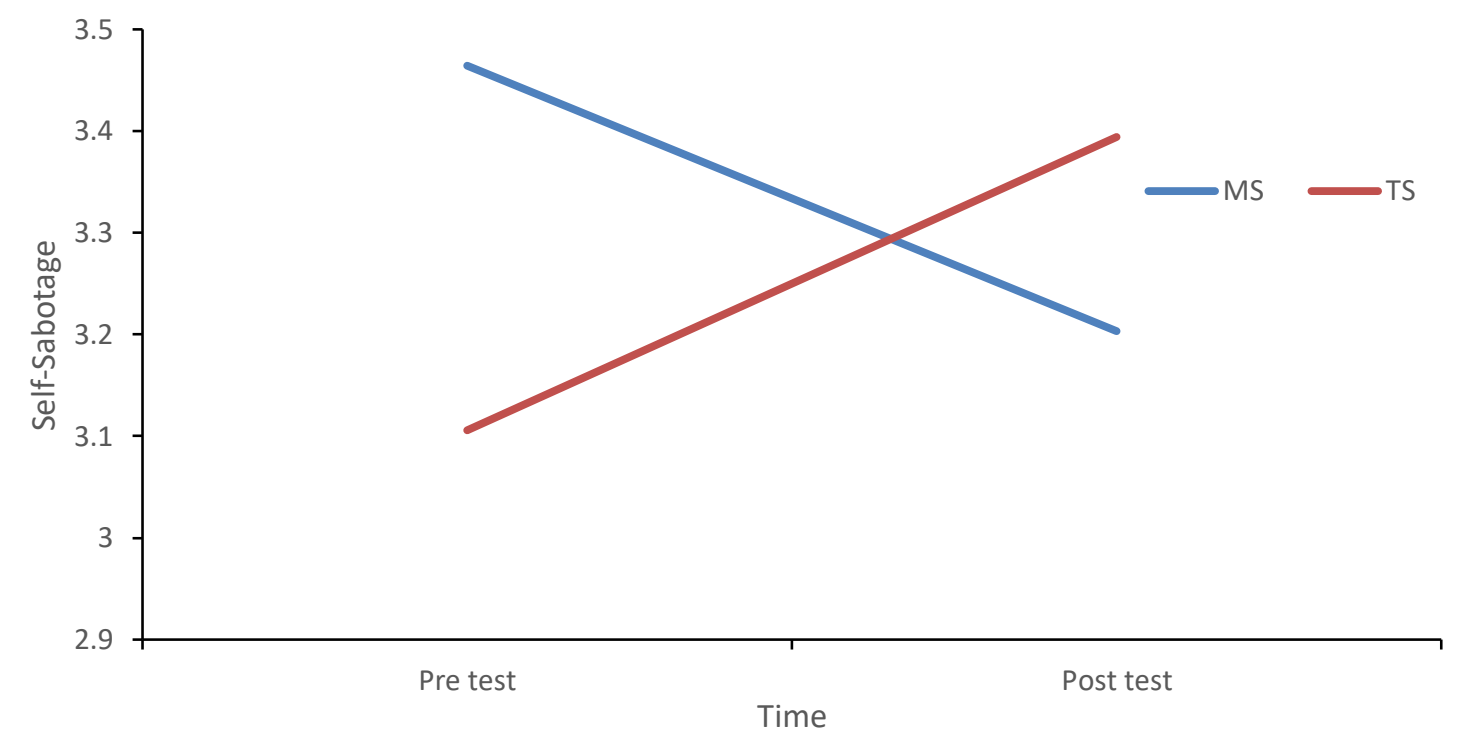

Figure 3. Mean scores for Uncertain Control at pre-test and post-test, separated by group condition 


\section{Analysis four}

Changes in self-sabotage as a dependent variable were analysed using a $2 \times 2$ ANOVA predicted by group type (between-subjects, 2 levels: MS and TS) and ethnicity (betweensubjects, 2 levels: Pasifika and non-Pasifika). There were no significant changes in selfsabotage by group or ethnicity, nor was there a group by ethnicity interaction (all $p$ 's $>.05$ ).

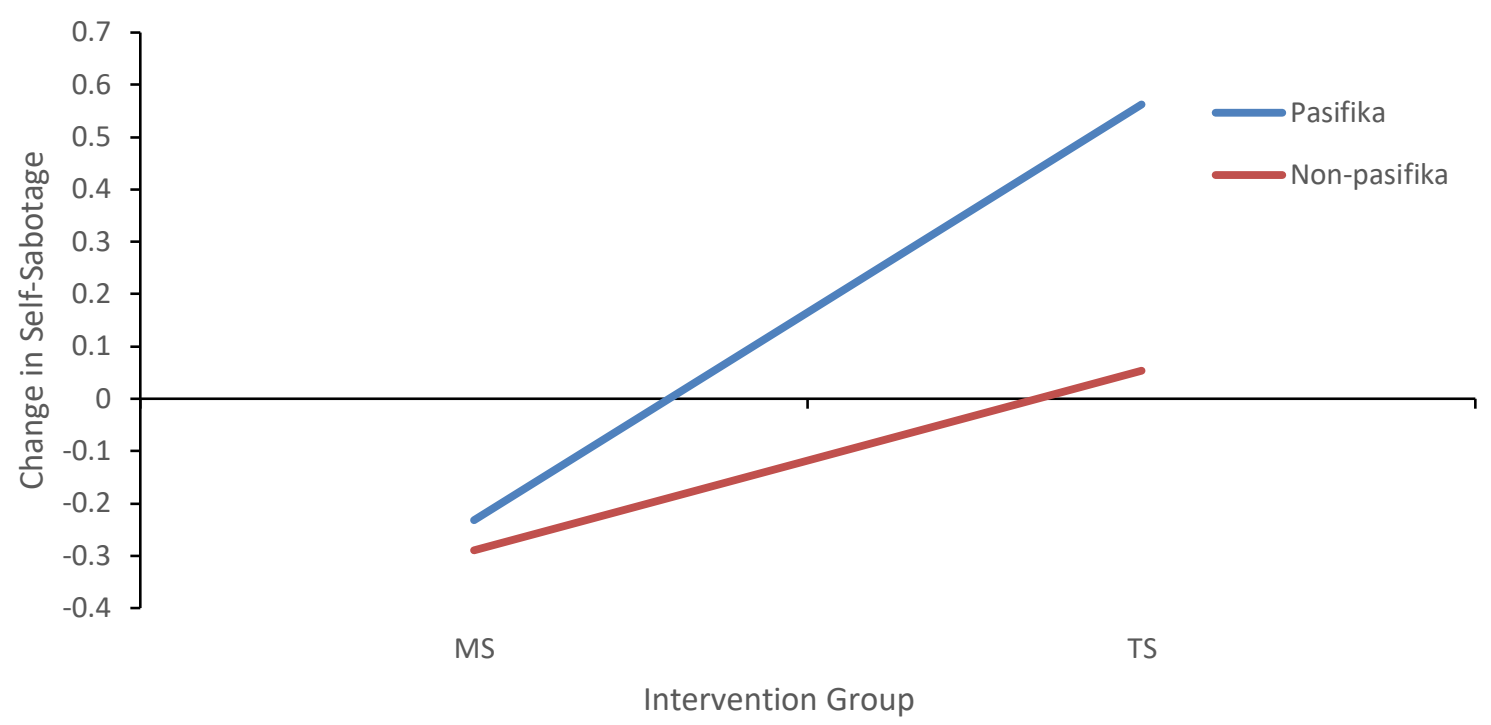

Note: Change scores were calculated by subtracting average Self-Sabotage scores at post-test from the average scores at pre-test

Figure 4. Mean change scores for Uncertain Control, separated by ethnicity

\section{Descriptive statistics about NCEA credits.}

NCEA Achievement Results - All students - (MS) vs (TS)

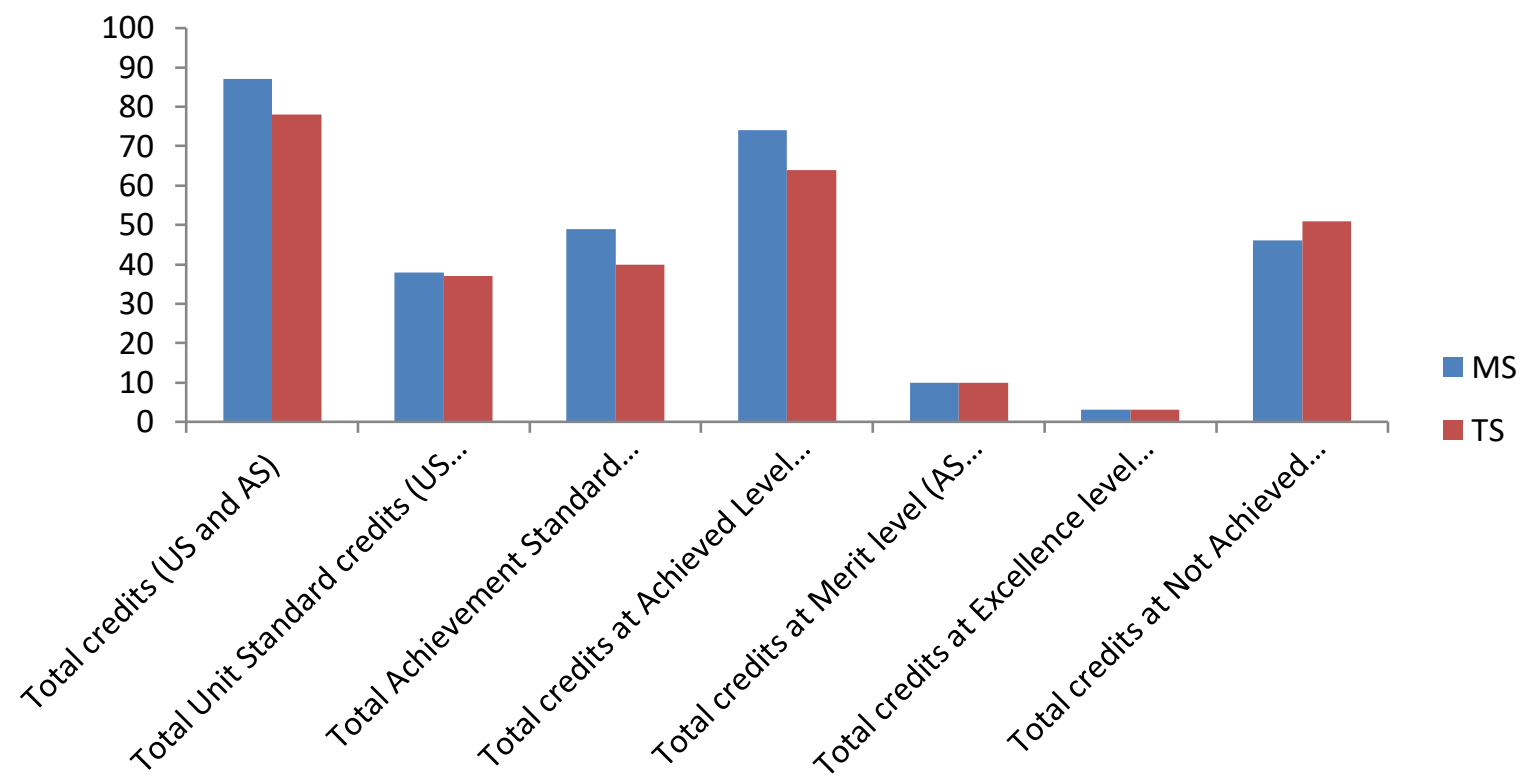

Figure 5. A description of NCEA achievement data for all students is shown in Figure five below 


\section{Analysis five}

The data were analysed in a series of linear regressions to test whether uncertain control and/or self-sabotage predicted NCEA outcomes for students. These showed that the intervention alone was not a significant predictor of the total number of credits obtained by students $(p=.360)$. However, post-test scores for uncertain control significantly predicted later credits gained ( $B=-9.31, S E=3.28, b=-.37, t=2.84, p=.006)$ and explained $13 \%$ of the outcome variance. Self-sabotage's post-test scores also yielded significant results when predicting the number of credits gained by students $(B=-7.33, S E=2.61, b=-.36, t=2.81, p$ $=.007$ ) and explained $13 \%$ of the variance in the outcome variable. When we combine uncertain control and self-sabotage in the model to both predict NCEA credit achievement, the predictor variables collectively explained $9 \%$ of the variance in the outcome variable.

\section{NCEA Achievement moderated by ethnicity}

The regression models reported in Analysis five were tested for moderation by ethnicity. Analyses six and seven tested if uncertain control or self-sabotage affected Pasifika and nonPasifika students differently.

\section{Uncertain Control}

\section{Analysis six}

The model that included uncertain control, ethnicity, and an interaction term between the two was significant $\left(F(3,50)=5.34\right.$, Adj. $\left.R^{2}=.20, p=.003\right)$. When viewing the individual predictor variables, uncertain control was a significant predictor $(B=-16.54, S E=4.68, B=$ $-.65, t=3.54, p=.001)$, while ethnicity was not $(p=.093)$. The interaction term, however, was a significant predictor for the number of credits obtained $(B=14.59, S E=6.36, b=.88, t=$ 2.30, $p=.026)$. This means that the ethnicity of the sample, either Pasifika or non-Pasifika, moderated the relationship between uncertain control and NCEA credit achievement, with Pasifika students having a stronger association than non-Pasifika students. Figure 6 depicts the results of analysis six below.

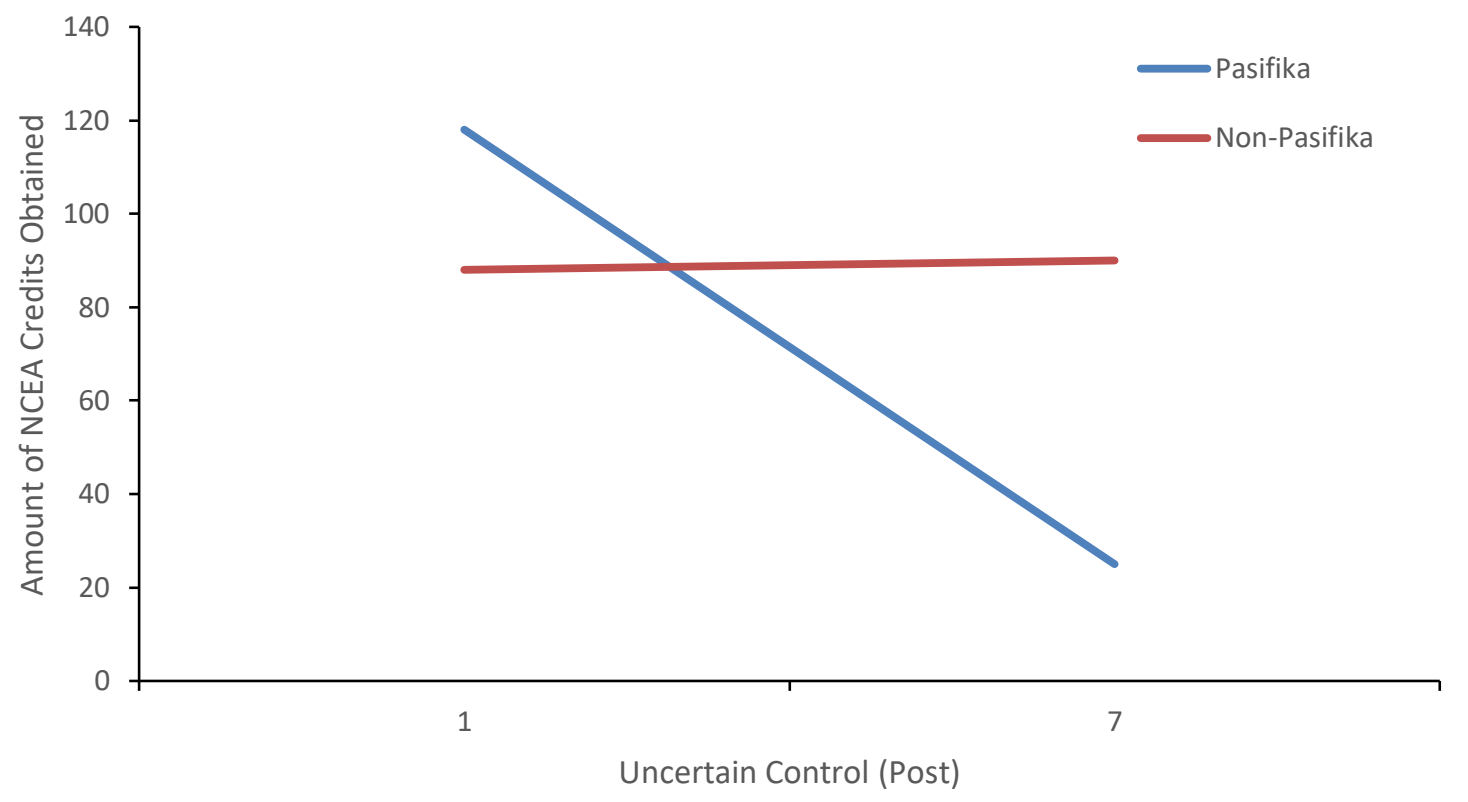

Figure 6. Ethnicity moderating the relationship between post Uncertain Control and the number of NCEA credits gained 


\section{Self-Sabotage}

Analysis seven

The model for self-sabotage and ethnicity was significant $\left(F(3,50)=3.48, p=.022\right.$, Adj. $R^{2}$ $=.12$ ) but only self-sabotage was a significant predictor $(B=-8.41, S E=3.50, b=-.42, t=2.41$, $p=.020$ ), indicating that ethnicity does not moderate the relationship between self-sabotage and NCEA credit achievement.

\section{Qualitative data analysis}

Several weeks after the interventions ended, the majority of students in both the MS and TS intervention programmes were interviewed about their experiences in the programme and what they thought about motivation and achievement. These Interview data were analysed with respect to alignment with, and contradictions to the quantitative data and existing theories of motivation and achievement, including identification of key messages about what motivates students to work hard at school.

The interview data were first analysed using NVivo 9, followed by initial line-by-line coding (Charmaz, 2006). This analysis produced five major themes - motivation, teachers, peers, programme, and culture. From these interview data it was possible to make direct comparisons with the quantitative data. For example, the quantitative data about effort could be compared directly to the qualitative data on this concept since "effort" was a word commonly used during interviews. However, sometimes it was necessary to re-analyse interviews looking for language which may have been more typical of what the 15-year-old New Zealand secondary school students in this study would have used. For example, one of the analyses investigated changes in aspiration. Initial analysis of the qualitative data found few participants used the actual term "aspiration". To work around this issue, the qualitative data were re-analysed using possible synonyms for "aspire" such as seek, aim, hope, desire, want, and wish. This second analysis of the interview data now showed many more possible references to aspiration. For example, when one student was asked the question, "Why do you work hard at school?" he answered "Because I want to pass. Like some other people, they don't care...I actually care about my work." This response was coded as indicating higher aspiration. In comparison, the response from the student who answered the same question with "I just can't be bothered because we were like half way through the project and I just gave up," was coded as lower aspiration.

\section{Discussion}

\section{Uncertain control}

Students in the MS intervention programme learned to decrease uncertain control by following a three-step strategy outlined by Martin (2014) - why l've done well or not so well in the past; what I can control; and keys to my control. Students were invited to write lists under two headings - things I can control versus things out of my control. Then students discussed these items - for example, the amount of study that a student might do would be considered within a student's control whereas the difficulty of the test is up to the teacher and out of the student's control. MS students were therefore encouraged to focus on those 
aspects they could control and were encouraged to practise controllable factors such as effort, so they could increase their sense of confidence that they could achieve well in tests and could succeed at school. As the detail of this material is copyright, the reader is referred to Martin (2014).

Analysis one of the quantitative data, which investigated changes in uncertain control over time between students in the MS and TS groups, showed that uncertain control decreased over time for all students of both the MS and TS groups. However, these data showed a decrease over time and not as a result of programme differences between the MS and TS groups for all students. We cannot know from this data analysis if this change in uncertain control is due to the effects in either intervention programme and may, for example, be due to other factors such as maturation of the students as they became more used to the rigours of assessment at level one of NCEA.

Analysis two of the quantitative data, which assessed any changes in uncertain control over time between Pasifika and Non-Pasifika students, showed that overall uncertain control increased more for Pasifika students compared to non-Pasifika students. However, the intervention mitigated this effect for Pasifika students. While the MS and TS interventions did not affect non-Pasifka students' uncertain control, the MS intervention had a positive effect on uncertain control; Pasifika students in the MS group had reduced uncertain control over time while Pasifika students in the TS group increased their uncertain control over time. The MS intervention programme affected only Pasifika students' uncertain control, with those in the MS group showing reduced levels to those in the TS group (with a strong effect size of 0.93).

Analysis five of the quantitative data showed that the intervention alone was not a significant predictor of the total number of credits obtained by students $(p=.360)$. However, post-test scores for uncertain control significantly predicted later credits gained. These data also showed that uncertain control accounted for $13 \%$ of variation in NCEA credit achievement among the sample. This indicates $87 \%$ is due to other factors, but clearly uncertain control has some sort of effect. For example, there was an overall main effect of ethnicity on uncertain control which means that, regardless of the intervention group that students were placed in, Pasifika students showed higher uncertain control than non-Pasifika students.

Analysis six of the quantitative data showed that being either Pasifika or non-Pasifika moderates the relationship between uncertain control and NCEA credit achievement. These data showed that uncertain control was only affecting Pasifika students - as uncertain control increases, the expected number of credits obtained decreases. However, for non-Pasifika students, the increase was unrelated to NCEA credits obtained. The data here do not show an effect by group, MS or TS, but is a function of ethnicity. The predictive data shown in the graph in Figure 6 may indicate the importance of teachers working with Pasifika students to reduce uncertain control, as this factor may be associated with better achievement outcomes.

Analyses of the qualitative data showed that it was not just the control messages that were important here but also how the messages were delivered. Some MS Pasifika students believed that teachers had a mediating effect on students' levels of control and achievement. In addition, some MS Pasifika students talked about "control" in association with the level of support they received from their teachers. For example:

You know like you need your teachers to guide to help you. 
Other qualitative data also supported the idea that the motivation-enhanced study skills programme may have contributed to the data showing a decrease in uncertain control. Pasifika students in the MS group explained that they gained control of their learning through the quality of the teaching they received. Students believed they could control their understanding through teachers who were helpful, explained repeatedly, prepared lessons well and teachers to whom they related positively.

It is likely that a student who fails enough times will simply stop trying as they may believe that they lack the control to do well in tests. Teachers must realise that they are central to enhancing students' motivation because the students may develop learned helplessness. Teachers may set up the learned helplessness situation in the first place if they are the agents of assessment and gatekeepers of success or failure. How does a particular teacher, especially in a secondary school situation where a student may have up to ten teachers, know what effect the award of a failed grade will be if the student has received that same message repeatedly?

The concept that teachers have a mediating effect on students' perceptions of control may also be extended to teachers having a mediating effect on students' perceptions of effort and ability attributions. The interview data suggested that teachers can negatively influence students' perceptions about their lack of ability. For example, two MS students reported that a teacher repeatedly ignored an underachieving Pasifika student in class and failed to give worksheets to this student. Another underachieving student reported that a teacher made disparaging remarks about his ability. Perry et al. (1993) suggested how teachers might make positive attribution comments during regular teaching classes: During and after class students often make statements such as: "I'm not smart enough to pass," "I was just lucky to do well on the test," or "The material is too difficult." Faced with such attributional statements, the instructor has an ideal opportunity to encourage the student to think differently about the event by suggesting a more suitable explanation: "You do have the ability; otherwise you would not be here," "Luck has less to do with your success than your approach (strategy) to the course," or "This may be a difficult course, but you can master the material if you study harder" (p. 718).

The findings reported here are consistent with other reports about students' views of internal versus external assessment and should be considered in light of proposed changes to NCEA. One of these proposed changes - that NCEA courses become $50 \%$ internally assessed and $50 \%$ externally assessed - may remove teachers' opportunities to influence uncertain control if a course was previously fully internally assessed.

There are differences in the way that New Zealand secondary school students view internal and external assessment tasks. For example, Hipkins et al. (2005) asked students to respond to the statement "I do well in internal assessments." Eighty-seven per cent of Year 13 students reported that they did well in internal assessments. When the same students were asked their response to another statement "I do well in external assessments," just 61\% of Year 13 students reported they did well. These comments appear to reflect ideas about the level of control students believe they have during an assessment situation and that proposed changes to NCEA that may reduce internal assessment are not what students prefer.

\section{Self-sabotage}

Martin (2014) explains that self-sabotage is when students do things that reduce their success at school such as "putting off doing an assignment or wasting time while they need to be studying for an exam" (p. 97). Martin (2009) believes that self-sabotage behaviours are 
associated with achievement because "If students self-sabotage they tend not to make the most of their ability, do not feel so good about being at school, and tend not to achieve as highly as they are able" (p. 97). Martin (2014) gave advice to teachers about how to tackle self-sabotage, for example, discuss with students who repeatedly leave school books and equipment at home to reflect upon why they do this and the effect this behaviour may have on their achievement. As the detail of this material is copyright, the reader is referred to Martin (2014).

Analyses three and four of the quantitative data about the effects of the intervention programmes on self-sabotage are not as useful as for uncertain control. The MS intervention programme self-sabotage data trends may indicate decreasing self-sabotage over time while the TS intervention increases; however, this was not statistically significant, as shown by all $p^{\prime} s>.05$. This lack of significance may be associated with the power of this study due to the small sample sizes. The quantitative data about effect sizes for self-sabotage were all around .30 to .44 , so not much can be concluded from these data.

Analyses five and six of the quantitative data gave a $p$ of .007 and showed that selfsabotage accounted for $13 \%$ of variation in NCEA credits. When combined they account for 9\%. This is to be expected as these analyses are combining two factors and SPSS is harsher when more predictors are added. What these data do indicate is that there is likely a lot of overlap between self-sabotage and uncertain control. This $9 \%$ is based on post-scores for uncertain control and self-sabotage, regardless of intervention, and may indicate that selfsabotage and uncertain control are associated with the total numbers of credits gained. However, analysis seven indicated that ethnicity does not moderate the relationship between self-sabotage and NCEA credit achievement, unlike the uncertain control data.

The qualitative interview supported the idea that the motivation-enhanced study skills programme may have contributed to a decrease in self-sabotage. The MS programme had provided opportunities for a sensitive topic, such as self-sabotage, to be openly discussed during the motivation enhanced study skills lessons, whereas the TS programme did not. Consider the following example of self-sabotage discussed by two MS Pasifika students ( $P$ and T):

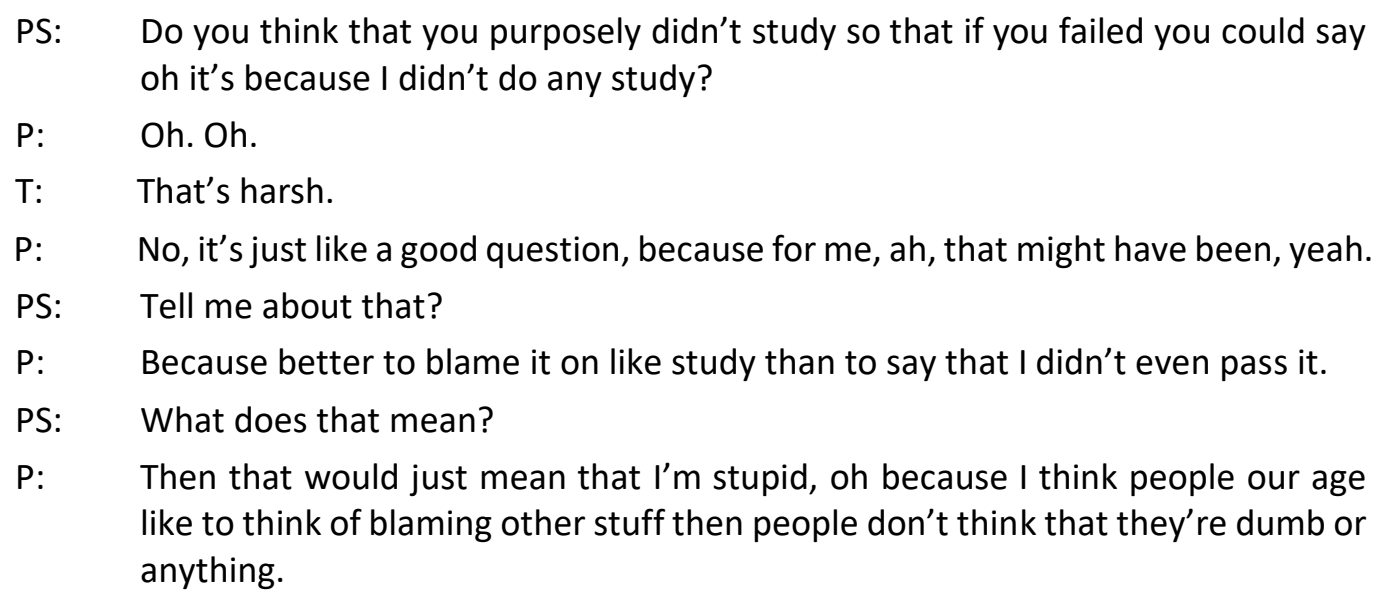

It is possible that the MS programme may have had some impact on MS student achievement because of discussion about motivation orientations around failure, whereas TS students did not have these opportunities. The decrease in self-sabotage may also have been associated with increased achievement since the two students interviewed ( $P$ and $T$ ) both passed Level 1 NCEA. 


\section{Teacher-student relationships and motivation and achievement}

A key finding from the qualitative data was that self-sabotage and uncertain control should not be considered deficits that are internal and stable. Instead, it would be educationally useful to regard these negative motivations as malleable as well as having been reinforced by their teachers throughout their schooling. Teachers can be more agentic in their approach to teaching and learning - the student interviews reveal that student perceptions of their teachers' attitudes and behaviours impacted on their maladaptive motivation orientations. Students also reported that their relationships with their teachers, and how their teachers communicated with them about learning, were important to their motivation and achievement.

Teachers could consider whether the quality of the teacher-student relationships in their classrooms is impacting on motivation and achievement. Certainly, students reflected on teacher-student relationships. In their interviews, many MS Pasifika students discussed these relationships, and 'teachers' was the most common theme mentioned by students. Some students associated teacher-student relationships with learning and achievement, reporting they liked teachers to whom they could talk. They also noted that when they could not relate easily to teachers, they believed their achievement suffered. However, students reported they were demotivated when teachers had differential teacher expectation of students, expressed annoyance or became irritated with students, or were impatient, did not push them to achieve, got 'off-topic', and asked them to peer-tutor other students:

I can't really talk to him much, that's why I don't get the work done.

Students also reported that they liked teachers who worked on being pleasant to students and made comparisons between teachers based on communication skills:

He just stands there and looks at your work, he doesn't really talk much. There's no 'hi how's your day?' kind of stuff.

These data showed that student achievement may be affected by more 'distant' teacher behaviour:

I couldn't hand in my assignment...I was like afraid to hand it in... I finished an assignment about a week later I handed it in because I am not comfortable around the teacher.

Differential teacher expectation was reported by some underachieving students who thought teachers only asked the smart people:

...because they think we do not know it.

This compared to teachers who expected all students to do well and treated students evenly:

Because they are fair between the students - like they don't have a favourite - like they don't treat you differently. 
Other students reported they received selective teaching:

There's students who are not passing everything, like students who don't get an aspect of it and (the teacher) kind of puts us aside.

These differential teacher expectation behaviours contributed to some students making personalised judgements about their teachers. For example, one underachieving Pasifika student reported that differential teacher expectation behaviours made him "feel dumb" and that in return "he went quiet in class." Other data showed that when teachers expressed annoyance or communicated irritation to students, they became demotivated and achieved less. Teacher impatience was most reported by students who asked teachers to reteach material or to explain concepts again:

If you didn't get things she just yelled and got angry. If you don't get it she just gives up and doesn't tell you how to do it properly.

Some students associated teacher irritation with student demotivation and underachievement:

The lessons just started and then (the teacher) starts yelling...and then that's going to be for the whole lesson, yeah, yelling, you get sore ears, you can't focus, and the only thing you want to do is walk out of the classroom - don't want to learn, don't want to learn.

Teachers can use the NCEA internal assessment process to manage disengaged students. Perry et al. (1993) reported that "Educators report that disengaged, underachieving students often make remarks such as "I'm not smart enough to pass," "I was just lucky to do well on the test," or "The material is too difficult"" (p. 718). Perry et al. suggest that when teachers hear these sorts of comments, they have an ideal opportunity to encourage the student to think differently about the event by suggesting a more suitable explanation: "You do have the ability; otherwise you would not be here," "Luck has less to do with your success than your approach (strategy) to the course," or "This may be a difficult course, but you can master the material if you study harder"'” (p. 718).

\section{Limitations}

It should be noted that only the tests identifying differences in uncertain control found a difference between Pasifika students and Non-Pasifika students and that self-sabotage did not show any significant effect. This should not be taken as evidence that the treatment has no effect on self-sabotage at all as it is possible that no significant effect size was obtained because of a lack of statistical power that was driven by a reduced sample size. While the results for self-sabotage were non-significant, one look at the figures shows an apparent trend that students benefitted from being placed in the MS group. Furthermore, some of the nonsignificant results were accompanied by moderate effect sizes which is an indication that the significant result was not acquired due to an insufficient sample size. A power analysis shows that to obtain a significant interaction with a relatively low effect size ( $\sim 15)$, a sample of at least 150 participants would be needed. While this present study lacks the adequate sample, 
the results are encouraging and should be taken as evidence that a large-scale study continue this further in the future. It should be noted that due to the resourcing available at the time of this research, it was simply not feasible to use 150 participants.

A second issue relating to the analyses is that the uncertain control ANOVA, with group and ethnicity as predictor variables, showed a marginally significant effect $(p<.10)$. In most cases, there should be no further analysis. For this study, we deemed it appropriate to conduct follow-up t-tests to test what may have been driving the interaction towards significance. The follow-up tests showed significant effects for only Pasifika students and this was accompanied by what is considered to be a large effect size (Cohen's $d=.93$ ). A high effect size in the absence of a truly significant interaction could be indicative of a poor sample size.

This research about the effects of a MS study skills intervention compared to a traditional (TS) study-skills programme may be described as a pilot intervention programme. The data in this article indicated that this research could be enhanced by replication in a larger range of schools, with more carefully controlled methodology, and over a longer timeframe. A larger scale research project with more students might more effectively demonstrate the value of a MS intervention but the research would need tighter methodology and more sophisticated statistical analyses.

\section{Conclusion}

This research was set in the context of the underachievement of some students in New Zealand secondary schools, particularly data that show that Pasifika students have lower achievement outcomes compared to students from most other ethnic groups. The research aimed to gain more data about what motivates Pasifika students to work hard and focused on how motivation is related to achievement.

Students who are underachieving in secondary school are likely to hold maladaptive motivation orientations that, unless changed, will have a negative impact on their future achievement. In this study 57 students from two schools with large Pasifika populations were offered supplementary teaching and learning opportunities via two different study skills programmes to improve their motivation and achievement. Participants (including 28 Pasifika students) were randomly assigned to either a TS or a MS programme.

Data about differences in NCEA achievement and changes in uncertain control and self-sabotage motivation outcomes for all students, and Pasifika students who participated in a TS support programme compared to students who participated in a MS support programme, were gathered and analysed. This article also reported student perceptions about uncertain control and self-sabotage motivation outcomes and how these affected their achievement in NCEA.

The most interesting findings of this research are that the MS intervention programme affected only Pasifika students' uncertain control, with those in the MS group showing reduced levels to those in the TS group. The data showed the MS intervention had a significant positive effect on reducing uncertain control for Pasifika students in the MS group over time while Pasifika students in the TS group increased their uncertain control over time. $(p=0.14$ and effect size $=0.93$ ).

In comparison, the MS and TS interventions did not affect non-Pasifka students' uncertain control. Analysis of non-Pasifika students found no significant difference between 
change in uncertain control scores for those in the MS group $(M=-.49, S D=1.49)$ compared to those in the TS group $(M=-.90, S D=1.52), t(27)=.74, p=.233$.

The data also showed that being either Pasifika or non-Pasifika moderates the relationship between uncertain control and NCEA credit achievement. For Pasifika students as uncertain control increases, the expected number of credits obtained decreases. However, for non-Pasifika students, the increase was unrelated to NCEA credits obtained, but the data here do not show an effect by group, MS or TS, but is a function of ethnicity.

Finally, Pasifika students in the MS group explained that they gained control of their learning through the quality of the teaching they received. Students believed they could control their understanding through teachers who were helpful, explained repeatedly, prepared lessons well, and teachers to whom they related positively.

Based on these findings, it is recommended that teachers make full use of internally assessed NCEA standards as the context for interventions designed to enhance student motivation and achievement. While the MS programme needs more research because of a lack of statistical power because of reduced sample size, the findings indicate teachers could use this research to decrease uncertain control as another tool to further address the underachievement of some students, especially Pasifika students.

The MS programme is ideally suited to be delivered via the teaching and learning processes associated with internally assessed standards to improve student motivation and NCEA. Teachers can consider the quality of their teacher-student relationships in a more holistic manner during an internally taught and assessed standard. When a standard is externally assessed and a student fails the assessment, it is not always possible to tell exactly where failure occurred. However, in an internally assessed standard, teachers can reflect upon the whole teaching, learning and assessment process and consider how agentic they were in their approach to teaching and learning.

\section{References}

Ajzen, I. (2011). The theory of planned behaviour: Reactions and reflections. Psychology \& Health, 26(9), 1113-1127.

Chu, C., Glasgow, A., Rimoni, F., Hodis, M., \& Meyer, L. (2013). An analysis of recent Pasifika education research literature to inform improved outcomes for Pasifika learners. Wellington: Jessie Hetherington Centre for Educational Research, Victoria University of Wellington.

Cronbach, L. J. (1951). Coefficient alpha and the internal structure of tests. Psychometrika, 16(3), 197-334.

Education Counts. (2019). Ngā Kura o Aotearoa: New Zealand schools (2018). A report on the compulsory schools sector in New Zealand. Wellington, New Zealand: Ministry of Education.

Hodis, F. A., Meyer, L. H., McClure, J., Weir, K. F., \& Walkey, F. H. (2011). A longitudinal Hodis investigation of motivation and secondary school achievement using growth mixture modeling. Journal of Educational Psychology. Advance online publication. doi.10.1037/a0022547

Martin, A. J. (2014). The motivation and engagement workbook (14 ${ }^{\text {th }}$ ed.). Sydney, Australia: Lifelong Achievement Group (www.lifelongachievement.com). 
Meyer, L. (2012, October). The NCEA as an exemplar of research into practice: Motivation, achievement and assessment design. In M. Hodis \& S. Kaiser (Eds.), Proceedings of the symposium on assessment and learner outcomes. Wellington, New Zealand: Victoria University of Wellington.

Meyer, L. H., McClure, J., Walkey, F., McKenzie, L., \& Weir, K. (2006). The impact of the NCEA on student motivation: Final report to the Ministry of Education. Wellington, New Zealand: Ministry of Education and Victoria University of Wellington.

Meyer, L. H., McClure, J., Walkey, F., Weir, K. F., \& McKenzie, L. (2008). Survey of NCEA goals: Year 10 and year 11 students. Wellington, New Zealand: Wellington College of Education.

Meyer, L. H., McClure, J., Walkey, F., Weir, K. F., \& McKenzie, L. (2009). Secondary student motivation orientations and standards-based achievement outcomes. British Journal of Educational Psychology, 79(2), 273-293.

Meyer, L. H., Weir, K., McClure, J., Walkey, F., \& McKenzie, L. (2007). Longitudinal research on the relationship between the NCEA and student motivation and achievement: Final Report to the Ministry of Education. Wellington: Ministry of Education and Victoria University of Wellington.

Meyer, L. H., Weir, K. F., McClure, J., Walkey, F., \& McKenzie, L. (2009). Motivation and achievement at secondary school: The relationship between NCEA design and student motivation and achievement: $A$ three-year follow-up. Wellington, New Zealand: Ministry of Education and Victoria University of Wellington.

NZQA (2019). NCEA change package 2019: Overview. Retrieved from https://conversation.education.govt.nz/assets/NCEA/NCEA-Change-Package-2019-Web.pdf.

Walkey, F. H., McClure, J., Meyer, L. H., \& Weir, K. F. (2013). Low expectations equal no expectations: Aspirations, motivation, and achievement in secondary school. Contemporary Educational Psychology, 38(2013) 306-315.

Peter Sanders, PhD, is Assistant Principal at St Mary's College, Wellington. His research is focused on designing, delivering, and evaluating practical evidence-based intervention programmes that improve motivation and achievement outcomes for Pasifika students in New Zealand high schools.

Email: peter.sanders@xtra.co.nz

Andre Boyte is a Masters student at Victoria University's school of Psychology. Andre's research area is with political psychology and voter decision-making processes, and he also contributes towards the Youth Wellbeing Study research group as a data analyst and research assistant.

Email: andre.boyte@vuw.ac.nz 